\title{
Development of Planar Illumination Strategies for Solving Mysteries in the Sub-Cellular Realm
}

\author{
Tanveer Teranikar ${ }^{\dagger}$, Jessica Lim ${ }^{\dagger}$, Toluwani Ijaseun and Juhyun Lee *D
}

Citation: Teranikar, T.; Lim, J.; Ijaseun, T.; Lee, J. Development of Planar Illumination Strategies for Solving Mysteries in the Sub-Cellular Realm. Int. J. Mol. Sci. 2022, 23, 1643. https://doi.org/10.3390/ijms23031643

Academic Editor: Kiryl Piatkevich

Received: 21 July 2021

Accepted: 25 January 2022

Published: 31 January 2022

Publisher's Note: MDPI stays neutral with regard to jurisdictional claims in published maps and institutional affiliations.

Copyright: (c) 2022 by the authors. Licensee MDPI, Basel, Switzerland. This article is an open access article distributed under the terms and conditions of the Creative Commons Attribution (CC BY) license (https:/ / creativecommons.org/licenses/by/ $4.0 /)$.
Department of Bioengineering, University of Texas at Arlington, Arlington, TX 75022, USA; tanveerashwini.teranikar@mavs.uta.edu (T.T.); jessica.lim@mavs.uta.edu (J.L.); toluwani.ijaseun@mavs.uta.edu (T.I.) * Correspondence: juhyun.lee@uta.edu; Tel.: +1-817-272-6534; Fax: +1-817-272-2251

+ These authors contributed equally to this work.

\begin{abstract}
Optical microscopy has vastly expanded the frontiers of structural and functional biology, due to the non-invasive probing of dynamic volumes in vivo. However, traditional widefield microscopy illuminating the entire field of view (FOV) is adversely affected by out-of-focus light scatter. Consequently, standard upright or inverted microscopes are inept in sampling diffraction-limited volumes smaller than the optical system's point spread function (PSF). Over the last few decades, several planar and structured (sinusoidal) illumination modalities have offered unprecedented access to sub-cellular organelles and 4D (3D + time) image acquisition. Furthermore, these optical sectioning systems remain unaffected by the size of biological samples, providing high signal-to-noise (SNR) ratios for objective lenses (OLs) with long working distances (WDs). This review aims to guide biologists regarding planar illumination strategies, capable of harnessing sub-micron spatial resolution with a millimeter depth of penetration.
\end{abstract}

Keywords: light sheet microscope; super-resolution; axially swept light sheet; oblique plane illumination; lattice light sheet; sub-voxel resolving technique; single-molecule localization light sheet

\section{Introduction}

Optical tomography has contributed tremendously to facilitating the non-invasive, quantitative modeling of tissue homeostasis and biochemical/mechanical mechanisms [1-7]. Furthermore, the ability to fluorescently label tissue in/ex vivo with minimal perturbation and high specificity [8-20], has opened doors to hitherto-unidentified cellular mechanisms. As a result, the biomedical research community has been able to characterize aberrant tissue and assimilate developmental biomarkers with high fidelity [21-29].

Traditionally, cellular mechanisms are identified in micron thick-tissue sections, using fluorescent dyes, antibodies or genetically encoded proteins [20,26,30-38]. However, histological findings are often predisposed to poor inter-/ intra-observer repeatability $[37,39,40]$. This is attributed to variations in section thickness, blade tilt angle, refractive index mismatch (RIM), and improper tissue handling and fixation protocols, as well as contaminants [41-48]. In particular, the degree of invasiveness involved in physical sectioning inhibits the orchestration of dynamic organogenesis. To this extent, fluorescence imaging has fulfilled the innate desire of biologists to probe anatomical abnormalities or metabolic dysregulation in vivo [2,8,35,49-51]

Conventional microscopes illuminating whole biological samples are prone to deleterious background noise from imaging planes beyond the plane of focus [52,53]. As a result, nanoscale organelles, proteins or molecular units in polymers spaced closer than 250-300 nm laterally $(\lambda / 2 N A)$ and $550 \mathrm{~nm}$ axially cannot be ordinarily resolved [54-58]. The last few decades have witnessed a metamorphosis of whole-slide imaging (WSI) into user-modulated, optical sectioning $[8,9,50,52,59-62]$ and patterned excitation strategies $[52,55,63]$. Periodic illumination modalities such as structured illumination microscopy (SIM) [64-66], stimulated emission depletion microscopy (STED) $[67,68]$, photoactivation localization microscopy 
(PALM) [69] and stochastic optical reconstruction microscopy (STORM) [70-72] have been developed to overcome the coveted Abbe diffraction barrier $[9,50]$. This is achieved through the modulation of higher optical frequencies into the visible frequency passband, through periodic, interference illumination patterns [52]. However, the abovementioned super resolution methods are derived primarily from widefield, two-photon or total internal reflection (TIRF) illumination strategies [36,55]. Hence, potential limitations include out-of-focus fluorescence and anisotropic nanoscale resolution for thick biological specimens/large fields of view (FOV) [55,73-75]. Moreover, a tradeoff is observed between spatio-temporal resolution, fluorescence labeling density and laser power required to avoid photo bleaching for a millimeter depth of penetration [56,59,73,76-80]. In this regard, planar illumination has successfully filled the niche for dynamic, subcellular fluorescence tomography.

Light sheet microscopy (LSM) has emerged as a very attractive optical technique due to abilities such as the reconstruction of $4 \mathrm{D}(3 \mathrm{D}+$ time $)$ organogenesis several millimeters deep inside tissue and isotropic nanometer resolution $[11,79,81,82]$. The non-ionizing nature of LSM modality enables non-invasive, genotypic and phenotypic biomarker screening, for vertebrate animal models and cell studies alike [8,80]. Consequently, LSM has been used to lift the veil on nuclear and cytosolic molecular assemblies such as the endoplasmic reticulum (ER) or mitochondria [13]. Furthermore, LSM has been used to visualize complex neuronal processes or dendritic spine pathophysiology in situ. Notably, such subcellular processes are routinely subject to noise and/or poor framerates for confocal laser scanning and widefield microscopy $[11,12,14]$. This review aims to cover recently developed planar illumination strategies that have enabled the rapid acquisition of subcellular volumes, hidden behind the optical barrier.

\section{Light Sheet Modality Considerations}

Light sheet fluorescence microscopy (LSM) utilizes hyperbolic optical sections with a Gaussian intensity distribution, for non-invasive sectioning (Figure 1B) [52,60,83-86]. Consequently, the collection objective lens (OL) (Figure 1B) acquires widefield, static (2D) images in the orthogonal perspective with respect to the illumination OL. In contrast, confocal modalities involve laterally scanned optical sections using a beam with an infinitesimal diameter [52,53]. Volumetric reconstruction typically requires sample translation through a stationary light sheet, with the help of stepper motors, piezo actuators, etc. [60]. Conversely, fixed samples are scanned rapidly by laterally displaced light sheets, analogous to the confocal line-scanning mechanism mentioned previously. The Gaussian light sheet is generated by inserting a mechanical slit in the optical train, to modulate the beam numerical aperture (NA) and the light sheet's thickness [51,60,62]. On the other hand, a cylindrical lens is used to focus the Gaussian beam onto the illumination OL back aperture $[14,86,87]$. Improvements to conventional LSM optical geometry include dual excitation (dLSM), for achieving isotropic contrast [60]. Excitation from two orthogonal perspectives reduces stripe artifacts observed by light propagation through heterogenous tissue refractive indices. Multi-view dLSM has gained popularity for isotropic volumetric resolution, allowing multiple imaging perspectives to be acquired via the angular rotation of the sample $[60,88]$.

In this review paper, we discuss 'single-lobe' light sheets obtained from Gaussian beams, alongside more complex, 'multiple-lobe' light sheets (Figure 1A). Single-lobe planar microscopy results in a monotonically reducing intensity distribution, following the Gaussian peak [84]. On the contrary, multi-lobe planar microscopy contains secondary intensity distributions following a main Gaussian peak. Such 'side-lobes' do not monotonically reduce and contain significant magnitude, as compared to Gaussian 'side-lobes' [84]. Hence, a lateral FOV for a collection OL can be described in terms of the confocal region, $\mathrm{b}=2 * \mathrm{Zr}=2 \pi(w o)^{2} / \lambda$, where $\mathrm{Zr}=$ Rayleigh length, $\lambda=$ wavelength and $\mathrm{w} 0$ is the beam waist $[52,53,83]$. The confocal region signifies near-homogenous illumination. Axial resolution can be defined as Raxial $=2 w o=2 \mathrm{n} \lambda / 2 \pi \mathrm{NA}$, thereby relating light sheet thickness to sectioning capability $[52,53,83]$. Increasing the FOV requires thicker light sheets; however, 
this reduces the axial resolution due to the low NA. For more complex light sheets, only the main Gaussian peak full width half maximum (FWHM) is usually considered [84].

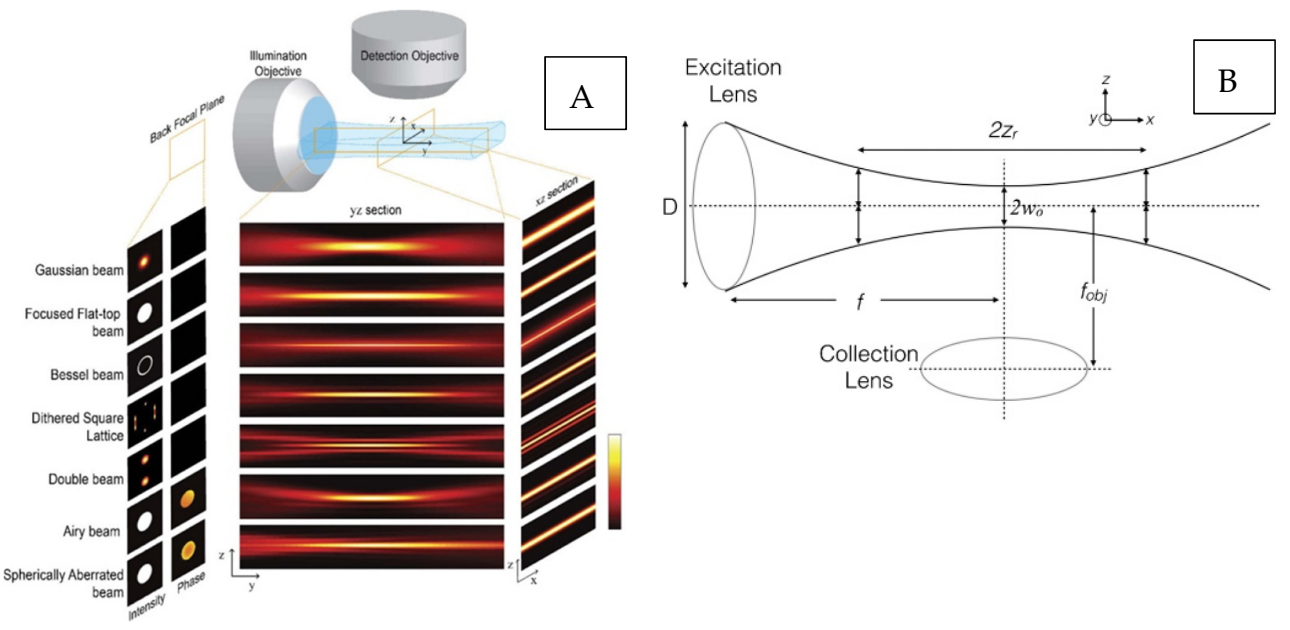

Figure 1. LSM beam profile characteristics. (A) LSM single lobe and multilobe top-view and sideview intensity distributions [84]. (B) Gaussian light sheet hyperbolic beam profile, $\mathrm{D}=$ lens diameter, $\mathrm{Zr}=$ Rayleigh length, $\mathrm{w} 0=$ beam waist, $\mathrm{f}=$ focal length of objective lens [83].

Most importantly, the LSM modality requires refractive index matching (RIM) between the sample, embedding medium and holder configuration, to increase photon collection efficiency (contrast) by camera pixels. Photon propagation through endogenous pigments, proteins, lipids, the cytoplasm and other molecules within tissue is inherently not conducive for RIM $[60,89,90]$. Consequently, tissue clearing has proven to be highly efficacious for reducing light absorption/scattering effects associated with widefield detection modalities and improving the depth of penetration. In comparison, optical sectioning through pinhole-based detection is highly robust against background fluorescence [60]. Over the last decade, several tissue-clearing methods, such as PEGASOS, CUBIC, CLARITY, uDISCO, vDISCO and CHAPS/SHANEL, have been developed to achieve sample transparency and reduce RI variability [89]. Organ transparency is achieved through bio-chemical interactions such as the disassociation of collagen, delipidation, decalcification, dehydration and decolorization [89]. Tissue clearing is highly beneficial for high throughput, non-invasive, genotypic or phenotypic mapping in toto [90].

Furthermore, several post-acquisition image processing techniques have been made accessible to microscopists in open source software platforms such as MATLAB and ImageJ (also known as Fiji). Image deblurring is performed via deconvolution using an optical system point spread function (PSF), obtained from imaging diffraction-limited beads embedded in agar- or resin-based embedding media [85,91]. Isotropic image contrast across an attenuated FOV is restored using intensity thresholding techniques such as histogram equalization or nonlinear haze removal [60]. Furthermore, median/Gaussian filtering, background subtraction or morphological operations such as image opening and dilation have been effectively used for noise removal [60].

\section{Axially Sweeping Light Sheet Microscopy}

LSM is a non - invasive tomographic technique that allows acquisition of optical crosssections, by confining fluorescence within 2D planar sheets in the sample [8]. LSM is routinely used to perform in situ/in vivo analysis of cellular structures or dynamic chemical processes, several millimeters deep inside opaque tissue [11,87]. However, LSM faces fundamental constraints imposed by the OL's numerical aperture (NA) and working distance (WD) [11,87].

Biologists/microscopists often face a dilemma in choosing the acquisition/detection OL's NA according to the object's size and WD. A high NA drastically reduces the effective WD of an optical system, restricting the light sheet penetration depth, albeit with increase 
in the spatial resolution due to the capturing of more light rays. On the other hand, lowNA OLs produce thicker light sheets with longer WDs, compromising the signal-to-noise ratio (SNR) for sub-cellular objects of interest [84]. As a result, a puzzling conundrum of choosing the appropriate NA without sacrificing spatiotemporal resolution is often encountered [11]. Using high-NA excitation optics improves axial resolution by producing thinner light sections. However, high NA tends to reduce the confocal parameter of the light sheet. Hence, imaging vertebrate animal models, such as mice, requiring a large WD benefits from low excitation NA OLs. On the other hand, high-NA detection optics are accompanied by a loss in effective WD for thicker specimens, apart from being costly.

To combat this, axially sweeping LSM (ASLSM) (Figure 2A) is emerging as a promising optical sectioning strategy for modulating the confocal parameter without sacrificing optical performance. ASLSM optical geometry comprises orthogonal illumination and detection geometry, similarly to conventional LSM $[8,11,87]$. The modification consists of aberrationfree remote focusing mechanisms, displacing the light sheet axially along the optical axis without moving the excitation OL WD. Hence, this enables the the arbitrary tuning of the usable field of view (FOV). The axially sweeping Gaussian light sheet is focused on the back aperture of the excitation OL using a cylindrical lens, akin to conventional LSM light sheet generation, as described in previous sections.

A

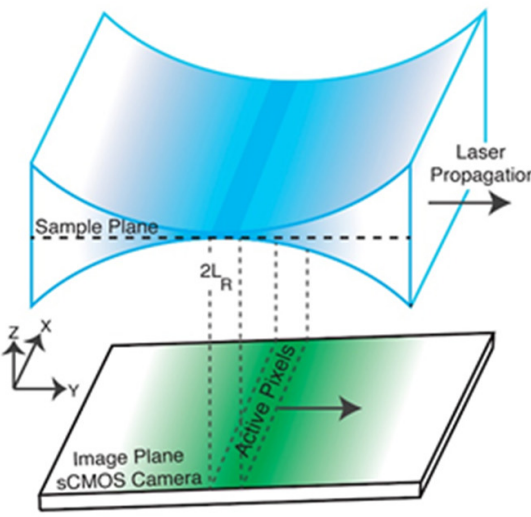

$2 \mathrm{~L}_{\mathrm{R}} \sim 8 \mathrm{Pix}=1.28 \mu \mathrm{m}$
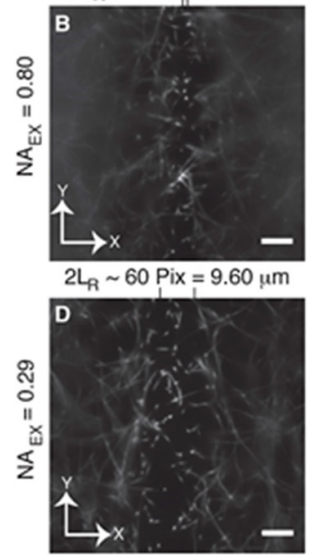
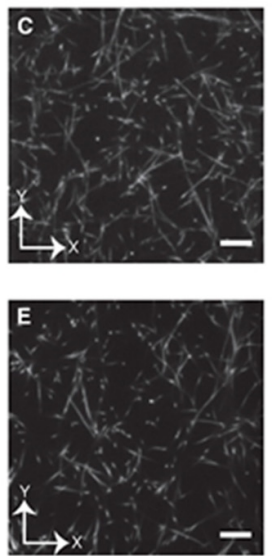

Figure 2. Illustration of ASLSM. (A) Schematic of ASLSM. Sample is illuminated with a laser from the $y$-direction and the fluorescence is taken perpendicular from a camera. $L_{R}$ is the Rayleigh length of the beam. The axial position of the beam is swept in the y-direction with a $2 \mathrm{D}$ array of pixels to create an FOV image. (B) Image of fluorescently labeled collagen with NA $=0.8$. (C) Image (B) with high optical sectioning. (D) Image of fluorescently labeled collagen with $N A=0.29$. (E) Image of (D) with high optical sectioning. (B-E) Scale bars are $10 \mu \mathrm{m}$ [87].

Early manifestations of ASLSM optical geometry, proposed by Dean et al. [87], consisted of averaging axial displacements of the light sheet with the camera's framerate. The light sheet refocus mechanism across the excitation FOV was realized through wavefront shifts produced by a piezo actuated mirror, through a secondary remote refocus excitation OL [11,87]. The authors reported a sub-micron lateral resolution of $380 \pm 20 \mathrm{~nm}$, matched by an axial resolution of $390 \pm 6 \mathrm{~nm}$ for a high-NA (0.8) excitation OL. Using a low excitation OL NA (0.29) did not result in a lateral resolution loss, although it showed a slight reduction in axial resolution to $919 \pm 8 \mathrm{~nm}$ [87] due to the reduced aperture of the optical system (Figure 2B-E). The authors comprehensively described the utility of achieving an isotropic $390 \mathrm{~nm}$ optical resolution across large confocal ranges $(\sim 10 \mu \mathrm{m})$ by studying the morphological and functional aspects of individual molecules during organogenesis [84]. ASLSM was able to visualize the anisotropic morphology of independent MV3 melanoma cells labeled with Tractin-eGFP, embedded in a collagen volume spanning $162 \mu \mathrm{m} \times 162 \mu \mathrm{m} \times 100 \mu \mathrm{m}[11,87]$. Moreover, ASLSM was capable of visualizing 
transient phenotypes of vimentin filaments, microtubules and mitotic spindles during epithelial-mesenchymal transition (EMT) [11,87].

Dean et al. further proposed a virtual-scanning ASLSM variant called diagonally scanned LSM (DSLSM) to improve camera framerates by avoiding the physical sample translation required for optical sectioning [12]. Digital light sheet scanning of a conventional 2D cell culture at 45 degrees with respect to the optical axis enabled impressive framerates $(3.1 \mathrm{~Hz})[12]$. As a result, DSLSM was able to capture actin and microtubule dynamics, clathrin-mediated endocytosis (CME) and phosphoinositide signaling [12]. Moreover, DSLSM was able to achieve a lateral resolution of $379 \pm 18 \mathrm{~nm}$ and an axial resolution of $725 \pm 29 \mathrm{~nm}$, using a dithered Gaussian lattice illumination mode for homogeneity [12].

Chakraborty et al. [11] further sought to improve previous ASLSM optical performance with the use of multi-immersion excitation OLs, and reported a landmark axial resolution of 260-290 nm using a high-NA (0.7) excitation OL [11,92]. The authors demonstrated the depth penetration ability of ASLSM via the volumetric reconstruction of neurons and dendritic spines, $2.5 \mathrm{~mm}$ deep in a PEGASOS-cleared Thy1-GFP mouse brain $[11,92]$. Furthermore, they highlighted the significance of achieving isotropic performance using a low-excitation NA OL by reconstructing individual neonatal kidney cells in a $3.4 \times 2.6 \times 2.5 \mathrm{~mm}$ volume. Other imaging highlights include the visualization of human stem cells (HSCs), nerve fibers and vasculature in PEGASOS-cleared mouse bone marrow at an isotropic $300 \mathrm{~nm}$ resolution using a high-NA (0.7) detection OL [11].

However, the axial displacement of the LS beam waist using mechanical remote focusing in previous ASLSM approaches is unable to match or exceed camera readout speed $[11,87,93]$. Hence, the physical motion involved in voice coil actuators, piezo motors and galvo mirrors requires the time averaging of displaced light sheet foci across the FOV [93]. Landry et al. demonstrated the use of linear phased arrays to achieve superb camera gating times of $350 \mathrm{kHz}$, enabling faster axial light sheet movement $(2.85 \mu \mathrm{s})$ compared to the camera pixel refresh rate $(9.6 \mu \mathrm{s})$. A 'rolling' shutter detection scheme was implemented via the modulation of the offset in activating camera pixels across the field of view (FOV) in synchronization with the moving light sheet focus. This enabled the authors to achieve a sub-micron lateral resolution of $504 \pm 17 \mathrm{~nm}$, and an axial resolution up to $720 \pm 55 \mathrm{~nm}-889 \pm 65 \mathrm{~nm}$ [93]. The novel axial scan setup was able to successfully capture 8- and 14-hour-old drosophila embryogenesis at impressive frame update times up to $9.6 \mu \mathrm{s}$.

The aforementioned ASLSM techniques have expanded the scope of nanoscale microscopy, which is often limited to low WD OLs. The integration of ASLSM with tissue clearing or tissue expansion methods can be used to perform tracking, analyze morphological changes or quantify chemical concentrations of individual molecules several millimeters deep in large biological volumes with high fidelity.

\section{Oblique Plane Microscopy}

Conventional LSM is based on non-collinearity between excitation and detection OL foci. Hence, the modality is fundamentally constrained towards low-NA excitation OLs with long working distances to avoid optical complexity [12,14,87]. Furthermore, in vivo volumetric reconstruction is adversely affected by the inability to capture light sections close to the coverslip, due to the tradeoff between high-NA detection OLs and WD [14]. HighNA lenses with small WDs significantly improve spatial resolution and single-molecule localization. However, potential drawbacks include the fabrication of custom cuvettes or immersion chambers, also affecting imaging sterility [14]. With respect to these issues, oblique plane microscopy (OPM) has been making tremendous strides in user-accessible, in situ/in vitro single-molecule localization and diffraction-limited imaging. The LSM modality uses the same NA OL for excitation and detection, enabling compatibility with traditional inverted or upright optical geometries. As a result, imaging complexity is greatly reduced due to its compatibility with commercially available/custom fabricated well plates and culture dishes. 
An elegant OPM solution for subcellular imaging was proposed by Gustavsson et al. [81,94] in the form of tilted LSM with 3D PSF (TILT3D) based on the integration of point spread function (PSF) engineering optics in the conventional LSM geometry. The authors propounded an unconventional approach by encoding the axial positions of irradiating sub-cellular objects in the structure of a PSF, and not the confocal parameter of a light sheet. The authors reported the use of double helix PSF (DH-PSF) for nanoscale imaging of a HeLa nuclear lamina ( 101-113 nm thick) and the mitochondrial membrane structure [81,94]. Furthermore, TILT3D provided localization accuracy of $3 \mathrm{~nm}$ in the $\mathrm{XY}$ direction and $7 \mathrm{~nm}$ in the $\mathrm{XZ}$ direction at $3.3 \mu \mathrm{m}$ above the coverslip, using a long-axial-range $(6 \mu \mathrm{m})$ tetrapod PSF [94].

Recently, Sapoznik et al. [14] proposed a user-friendly OPM optical geometry (Figure 3A-C) method; the primary (excitation and detection) OL (Figure 3A) is used for aberration-free volume scanning. Furthermore, it is also used for forming an intermediate imaging plane with a secondary OL (Figure 3B). The volumetric image formed at the focus of the secondary OL is imaged on camera pixels by a tertiary OL (Figure 3C) [14], thereby avoiding the de-coupling of excitation and detection imaging planes. A custom OL was placed before the camera to increase the effective NA of the optical geometry, by capturing marginal rays that may escape during the virtual light sheet scan. The single-NA optical strategy reported an astounding lateral resolution of $\sim 203 \pm 24 \mathrm{~nm}$ to $209 \pm 33 \mathrm{~nm}$ and an equally impressive axial resolution up to $523 \pm 60 \mathrm{~nm}$ for a large field of view (FOV) of $180 \mu \mathrm{m} \times 180 \mu \mathrm{m}$, after 20 iterations of Richardson-Lucy deconvolution [14]. The novel OPM technique was used to capture sub-diffraction-limited organelles such as the endoplasmic reticulum in osteosarcoma U2OS cells, vimentin in retinal pigment epithelial cells or the nuclear constriction/herniation mechanisms of melanoma cells in micropore $(\sim 2-2.5 \mu \mathrm{m})$ environments [14]. Moreover, light sheet virtual scan, as opposed to physical sample translation, enabled high camera framerates ( $\sim 800 \mathrm{fps})$ [14]. As a result, the novel OPM method was able to capture calcium translocation due to rat cardiomyocyte contraction assess cytosolic rheological properties and perform the optogenetic activation of Rac1 [14]. The ability to image centimeter-thick tissue without additional image perspectives and integration with traditional coverslip mounting schemes surpasses the native performance metrics of OPM methodologies.

An alternative approach to the single-OL OPM approach proposed by Sapoznik et al. [14] was recently put forth by Yang et al. [95] through the multi-view SR OPM configuration. The authors reported the ability to capture large imaging volumes up to $3000 \mu \mathrm{m} \times 800 \mu \mathrm{m} \times 300 \mu \mathrm{m}$, at a noteworthy resolution of $\sim 450 \mathrm{~nm}$ laterally and $2 \mu \mathrm{m}$ axially [95]. The epi-illumination, DaXi OPM optical geometry was used to capture somatogenesis, along with zebrafish larval embryogenesis and tail development [95] (Figure 3D-I). Furthermore, the ability to switch from upright to inverted illumination allowed simultaneous time-lapse microscopy of nine zebrafish embryos in a glass-bottom Petri dish [95]. 
A

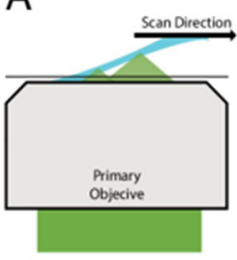

B

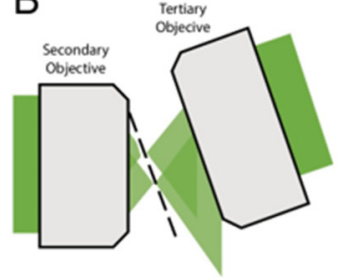

C

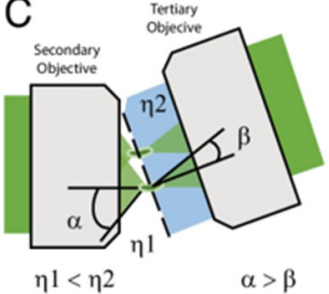

D
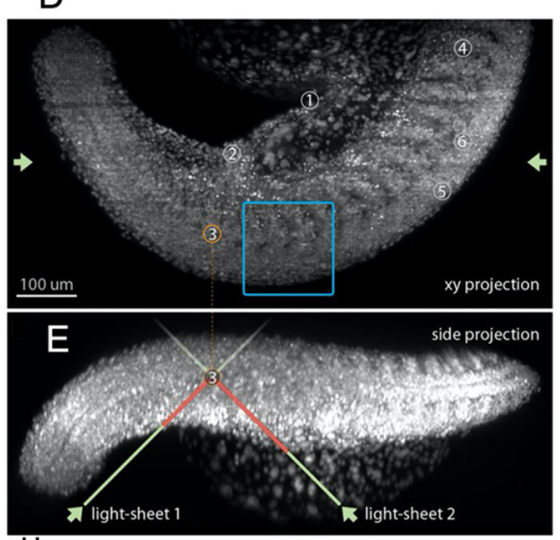

$\mathrm{H}$

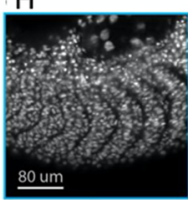

$0 \min$

$0 \mathrm{~s}$

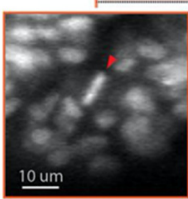

$66 \mathrm{~min}$

$80 \mathrm{~s}$
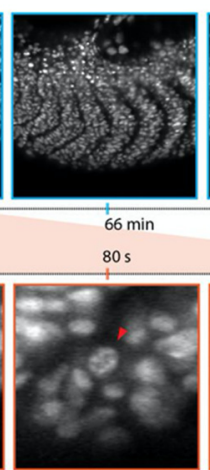

$\mathrm{F}$
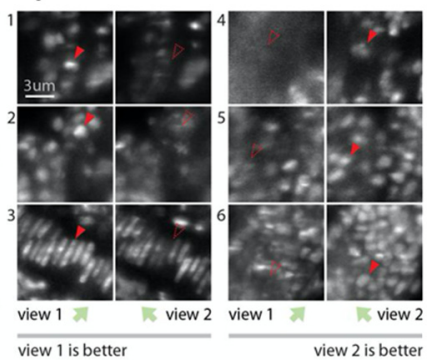

G
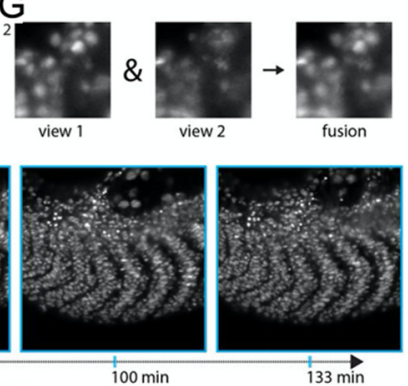

$120 \mathrm{~s}$ $160 \mathrm{~s}$
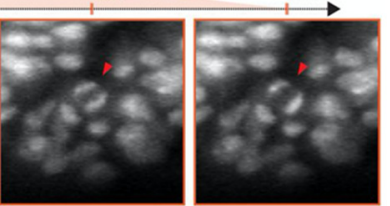

Figure 3. Two illustrations of OPM. (A) The light sheet (blue) is from the primary objective lens illuminated at an oblique angle. (B) Traditional OPM-Primary objective lens fluorescence is replicated when secondary objective lens crosses with tertiary objective lens. (C) Optimal microscope resolution (from $\alpha$ to $\beta$ ) created when light moves from a low refractive index, $\eta_{1}$, to a high refractive index, $\eta_{2}$. (A-C) [14] (D) Zebrafish tail at 24 hours post-fertilization with $m$ Cherry-labeled histones. (E) Side projection of light sheets entering sample at 45 degrees. (F) Example regions where (left) View 1 has better image quality, whereas (right) View 2 has better image quality. (G) Fusion of View 1 and View 2 with better image quality. (H) Time-lapse of dorsomedial tail. (I) Spatio-temporal image of a cell division. (D-I) [95].

Kim et al. [13] further developed an OPM method (obSTORM) capable of delivering a light sheet tunable between 45-90 degree tilt angles. obSTORM reported a resolution of $\sim 44-51 \mathrm{~nm}$ for tissue depths of $32 \mu \mathrm{m}$, for 45 degree tilt angles. In addition, the authors reported that obSTORM was able to provide an isotropic localization accuracy of $\sim 18.5 \mathrm{~nm}$, hence resolving microtubules ( $\sim 69 \mathrm{~nm})$ spaced $128 \mathrm{~nm}$ apart in fixed A549 cells, along with the mitochondria [13]. The effective FOV of OPM depends on the beam offset at the OL back aperture and the resultant light sheet tilt angle [96]. Although geometrical considerations for OPM FOV are outside scope of this review, the optimization of tilt angles according to sample thickness has been put forth by Kumar et al. [96].

The above-mentioned SR OPM methods have great potential to perform the dynamic imaging of targeted samples or the imaging of whole mounted samples. The sub $200 \mathrm{~nm}$ 
resolution far exceeds traditional widefield or epi-illumination optical limits, ushering in new paradigms for disease modeling in tissue pathophysiology.

\section{Lattice Light Sheet Microscopy}

LLSM has enabled biologists to probe biological volumes across different scales in vivo, due to its excellent optical sectioning $(<5 \mu \mathrm{m})$, minimal phototoxicity, intrinsic autofluorescence rejection and sub-second imaging rates $[78,79]$. The LLSM modality produces concentric beam distributions through constructive and destructive interference (Figure 4). However, LLSM is fundamentally constrained by the lens NA, limiting the isotropic nanometer resolution to several hundred microns at best, owing to Gaussian beam waist divergence beyond the Rayleigh range [79].

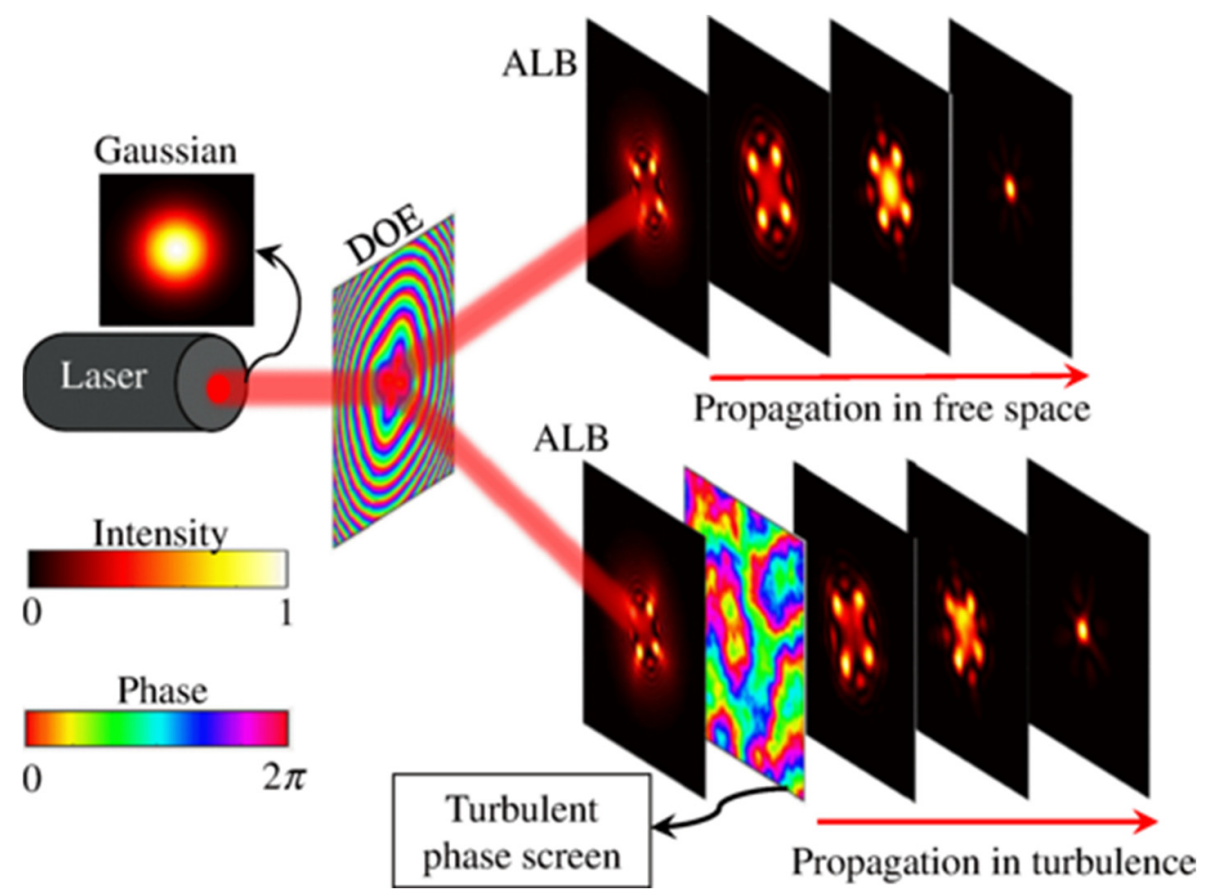

Figure 4. Illustration of how aberration laser beams (ALBs) were produced and propagated in free space and turbulence after passing through an incoming excitation Gaussian beam into a diffractive optical element (DOE) [77].

Chen et al. [78] developed sub-micron lattice light sheet microscopy to overcome traditional light sheet drawbacks such as the Gaussian beam scattering tendency and optical section thickness. LLSM relies on extremely thin $(0.4-1 \mu \mathrm{m})$ optical sections [78,97], created via the modulation of phase masks on the OL aperture that propagate indefinitely without undergoing a change in the beam cross sections $[61,88]$. The authors reported impressive lateral and axial resolutions of $230 \mathrm{~nm}$ and $\sim 370 \mathrm{~nm}$, respectively, for a dithered optical lattice, and a remarkable $150 \mathrm{~nm} \times 280 \mathrm{~nm}$ axial $x z$ resolution for SIM mode (xz axis) [78]. Furthermore, the authors emphasized the 'self-healing' nature of the lattice excitation by describing an astonishing beam width (full width half maximum) of $\sim 1 \mu \mathrm{m}$ for a propagation distance of $50 \mu \mathrm{m}$ [78]. Practically, LLSM light sheet propagation length homogeneity depends on modulating the thickness of a ring annulus (ring mask). This is analogous to varying the mechanical/camera pixel rolling shutter slit width in traditional LSM microscopy $[78,79]$. The optical lattices are periodic fringe patterns produced by the superposition of Bessel beam side-lobes or spatial light modulation before the ring annulus. The authors reported that they were able to observe unrevealed molecular phenomena such as the diffusion and binding kinetics of TMR-Halo-labeled Sox2 transcription factors in $35 \mu \mathrm{m}$ thick spheroids, mitochondria and endoplasmic reticulum. The authors also described the ability to track changes in chromosome morphology during each phase of 
mitosis for HeLa cells or neutrophil migration through a 3D collagen mesh $(\sim 8-12 \mu \mathrm{m}$ travel distance). They suggested the integration of adaptive optics (AO) for improving refractive index aberrations [98].

Liu et al. highlighted the importance of AO-based LLSM [98], similar to the piezo actuators or galvo mirrors mentioned in previous ASLSM and OPM sections, by visualizing clathrin and dynamin in endocytic pits. They emphasized the lack of poorly defined cell boundaries and the lack of differentiation between membrane structures and cytosol in the absence of aberration-free remote refocus optics [98]. The group proceeded to visualize clathrin-coated pits and vesicles in the dorsal tail region of a zebrafish tail $80 \mathrm{~h}$ post-fertilization (Figure 5), along with subcellular organelles such as mitochondria [98]. However, the Bessel mode of illumination for LLSM affects beam attributes such as FOV and beam propagation length. Other potential limitations include the presence of secondary intensity side-lobes (broad side tails), along with a central intensity maximum due to the thickness modulation of the previously-mentioned ring annulus structures [79].

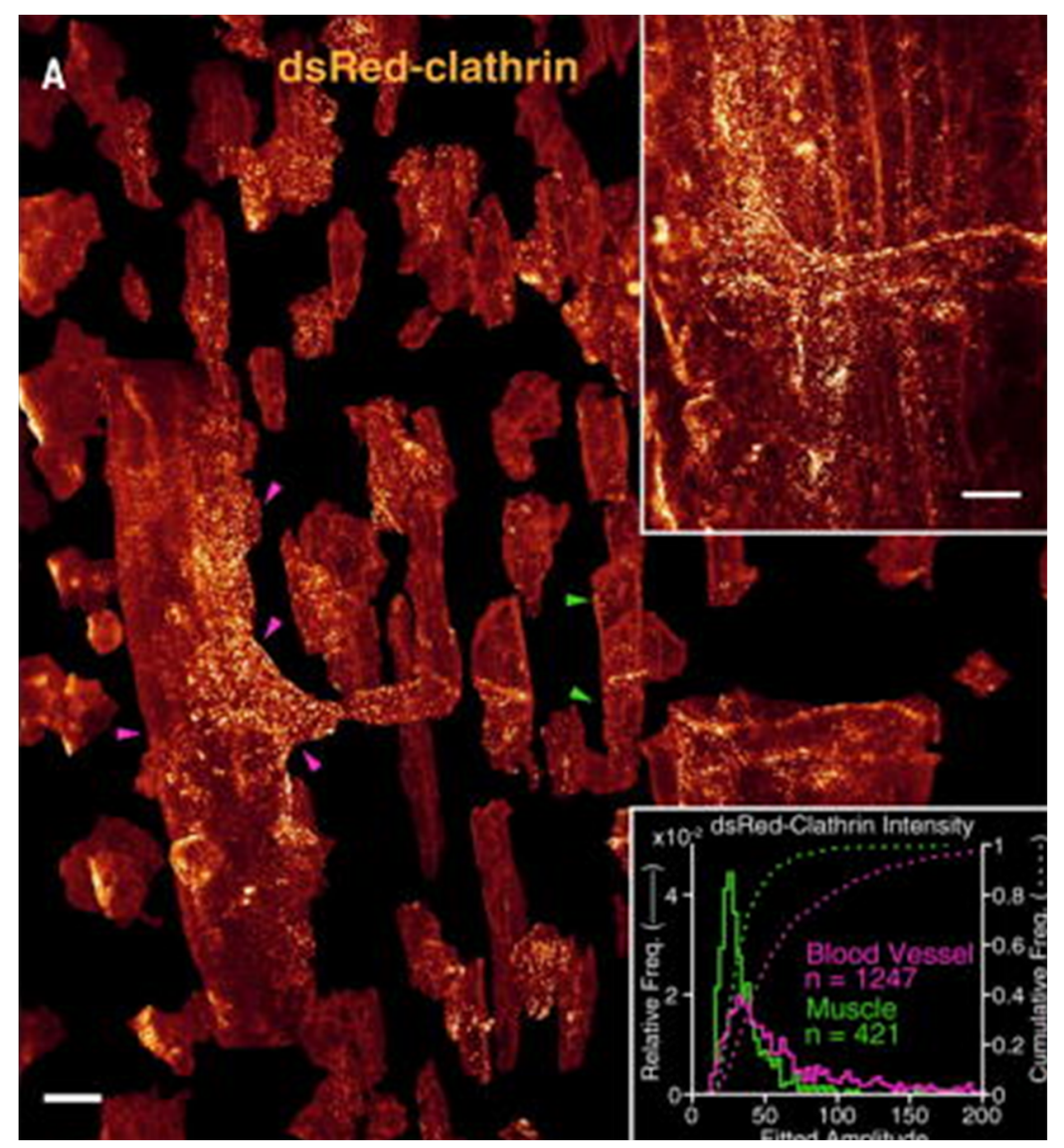

Figure 5. This figure shows separated muscle fibers (examples are shown with green arrowheads) and vascular endothelial cells (examples are shown with magenta arrowheads) that express DsRed-CLTA. The upper right corner shows $75 \mu \mathrm{m}$ by $99 \mu \mathrm{m}$ by $41 \mu \mathrm{m}$ of the tail of a developing zebrafish, whereas the bottom right corner shows a graphical depiction of clathrin puncta in the endothelial cells [98]. Scale bars are $10 \mu \mathrm{m}$.

To overcome these limitations, Betzig et al. proposed the integration of a structured illumination mode (SIM) for lattice light sheet microscopy [99]. Three successive phase shifts of discrete, periodic fringes (the fringe separation is less than $\lambda / \mathrm{NA}$ ) in a single camera's exposure period, resulting in a landmark $270 \mathrm{~nm}$ full-width at half-maximum (FWHM) [99]. The authors, however, argued that the SIM mode for Bessel-beam-based LLSM was prone to low-SNR image frames due to fringe separation less than $\lambda / 2 \mathrm{NA}$. Hence, they sought to improve the contrast of image frames for thicker, multicellular 
biological samples by means of two-photon illumination (multi-harmonic excitation) [99]. The authors tested the performance of the Bessel-beam-based SIM and two-photon LLSM through a comparison with conventional confocal and digitally scanned LSM. The optical group observed significant phototoxic effects for the confocal imaging of dynamic LLC-PK1 cells, due to the presence of fragmented mitochondria [99]. In contrast, Bessel illuminationbased LLSM resulted in non-perturbation of the mitochondrial morphology, along with the preservation of the original intensity ( $80 \%$ photon count) even after the acquisition of 300 biological volumes (individual volumetric stack 321 images) [99]. Furthermore, the authors reported the ability to track the endoplasmic reticulum (ER) evolution of human osteosarcoma (U2OS) cells, using SIM mode at $300 \mathrm{~nm}$ isotropic resolution. Using twophoton excitation, the authors were able to study unrevealed biological phenomena-the retrograde flow of membrane ruffles causing micropinocytosis in an African green monkey kidney cell, the 3D dynamics of chromatid separation during early anaphase and the actin-based filopodia of HeLa cells [99].

More recently, a study was published detailing the integration of LLSM and tissue expansion for whole-brain imaging [100]. The authors reported a $60 \mathrm{~nm} \times 60 \mathrm{~nm} \times 90 \mathrm{~nm}$ optical resolution for a $4 \times$ tissue expansion. Moreover, they were able to quantify volumes of subcellular organelles, such as mitochondria, and characterize morphological properties for 1500 dendrites in the mouse brain cortex, as well as the longitudinal myelination of axons [100].

Nanoscale expansion microscopy uses hydrogels to isotropically expand the cellular structure within the specimen, and is capable of resolving structures up to $25-60 \mathrm{~nm}$ using conventional optical sectioning techniques [101-103]. Single-iteration protocols lead to $\sim 4.5 \times$ expansion, whereas multiple iterations $(\sim 20)$ can produce expansion up to $10 \times$ [103]. In conjunction with the tissue-clearing techniques mentioned previously, tissue expansion microscopy is a very powerful tool for enabling access to subcellular organelles in millimeter-sized samples, which primarily requires long-WD OLs.

Hence, SR LLSM is emerging as a powerful imaging tool in conjunction with tissueclearing/expansion methods to learn about the hidden intricacies of biological tissue obscured behind the resolution limit. The independence of the beam intensity profile on lens WD greatly facilitates the nanoscale reconstruction of whole organ systems without a loss in magnification. However, side-lobes in spatial distributions' of 'self-healing' beams such as Bessel and lattices, reduce the optical sectioning resolution. Hence, propagation-invariant beams require post-processing deconvolution, and this warrants further investigation.

\section{Sub-Voxel-Resolving Light Sheet Microscopy}

Sub-voxel-resolving light sheet microscopy (SVR LSM), enables the improvement of spatial resolution through graphics processing unit (GPU)-based computation [82,104], thereby avoiding time-intensive image processing. This modality requires a tilting plate ( 10 degrees inclined surface) attached to the sample mount in order to ensure an off-axis scan $[82,104,105]$. The off-axis scan with the tilting plate enables rapid sub-voxel shifts in both lateral and axial directions [82]. The off-axis shifts are used by the SVR algorithm to reconstruct the final high-resolution output image [82,104,105].

Fei et al. first introduced sub-voxel LSM (SLSM) and revealed that the technique was able to successfully enhance the resolution of a 3D cultured normal human bronchial epithelial (NHBE) cell spheroid [82]. Furthermore, they performed multi-view SLSM and were able to improve the resolution by between four and nine folds, allowing the recovery of human umbilical vein endothelial cell (HUVEC) sprouts. The authors have also reported that SLSM was able to achieve a wide FOV ( 233 mm volume), with a low-magnification detection objective lens (NA: 0.1), with a resolution similar to a higher-magnification detection objective lens (NA: 0.45) [82].

Nie et al. demonstrated an improved resolution $(0.975 \mu \mathrm{m}$ voxel $)$ in a cleared whole mouse brain (Tg: thy1-GFP-M), with the implementation of multiangle-resolved sub-voxel selective plane illumination microscopy (Mars-SPIM) [104]. This technique combines the sub-voxel-resolving (SVR) algorithm and the multiview Bayesian deconvolution (MVD) 
method, bypassing tedious image stitching or interpolation. The continuous capturing of low-resolution images allowed for a total of eight views in whole mouse brain imaging [104]. They also pointed out that the Mars-SPIM technique facilitated the visualization of the clearly resolved neurons in the cortex area by approximately four-fold when compared to conventional SPIM (Figure 6). Thus, this study successfully demonstrated the usage of a computational algorithm to accelerate the performance of a super-resolution microscopy technique without requiring more additional implementation towards optics features.
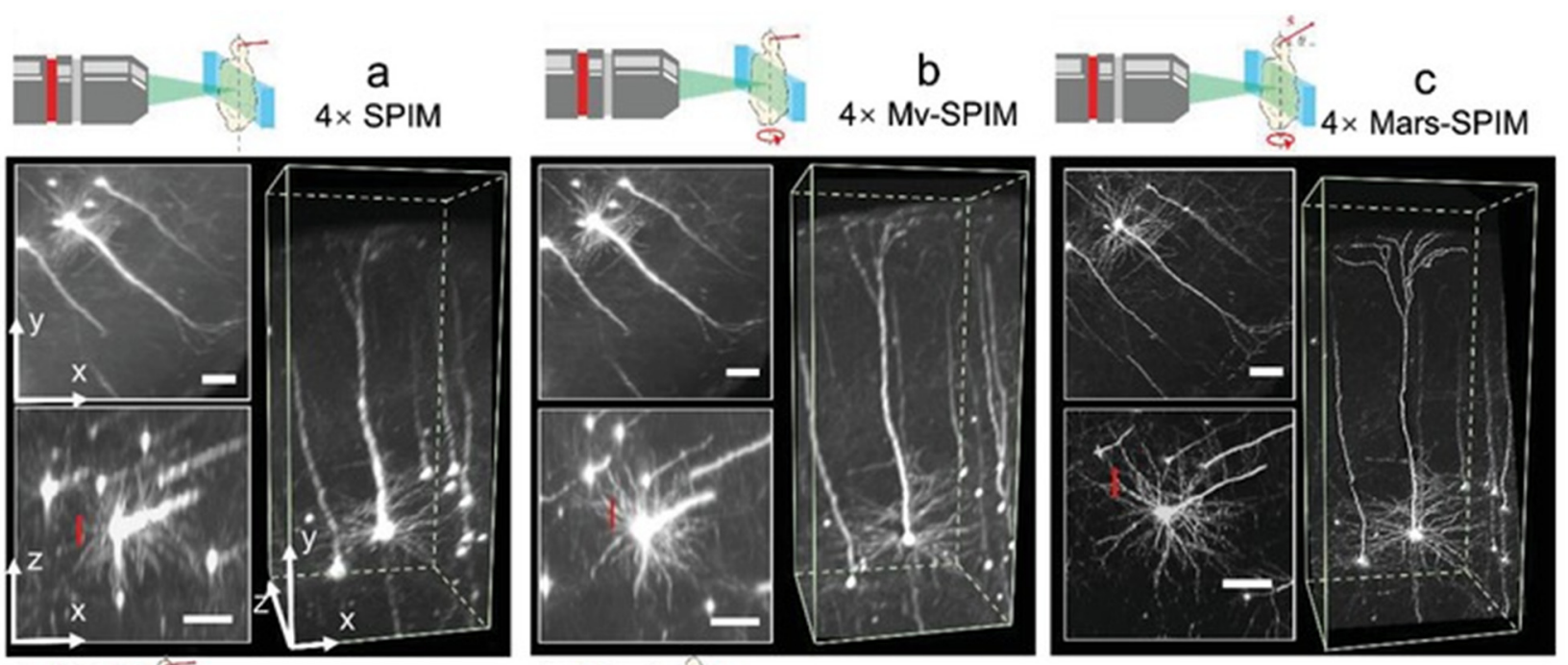

Figure 6. Visualization of neurons on Tg:thy1-GFP-M mouse brain. (a) $4 \times$ imaging on benchtop SPIM with a voxel size of $1.625 \mu \mathrm{m} \times 1.625 \mu \mathrm{m} \times 6 \mu \mathrm{m}$. (b) $4 \times$ imaging with multiview SPIM with a voxel size of $1.625 \mu \mathrm{m} \times 1.625 \mu \mathrm{m} \times 1.625 \mu \mathrm{m}$. (c) $4 \times$ imaging with Mars-SPIM with a reconstructed voxel size of $0.41 \mu \mathrm{m} \times 0.41 \mu \mathrm{m} \times 0.41 \mu \mathrm{m}[104]$.

In another SVR LSM study, conducted by Zhao et al., his group developed a sub-voxelresolving light-sheet add-on microscopy method (SLAM) that enables light-sheet imaging on conventional fluorescence microscopes [105]. This technique is carried out by designing a portable add-on device that is mounted onto the stage of the inverted microscope $[105,106]$. The portable device consists of optical components that would have normally been included on a tabletop LSM setup. This setup also includes the customized tilting plate that enables the oblique scanning of the sample, allowing the sub-voxel step shift for super-resolved images. The authors reported the high-throughput mapping of a uDISCO cleared half mouse brain with labeled neurons GFP (Tg:thy1-GFP-M) with a super-resolved voxel size of $0.54 \mu \mathrm{m} \times 0.54 \mu \mathrm{m} \times 3 \mu \mathrm{m}$ [105]. Furthermore, the SVR algorithm facilitated the resolving of neuronal dendrites that were not clearly visualized in the unprocessed raw images [105]. With its low cost and simple optics advantages, this adaptable add-on device can be utilized on most conventional microscopes for super-resolved images that resemble those obtained using a confocal microscope.

SVR LSMs have been successfully shown to have promising results, surpassing a regular LSM resolution limit by introducing oblique sample tilting and the implementation of a high-throughput reconstruction algorithm flow. The preservation of a large FOV with a subcellular resolution enables the imaging of larger samples that contain detailed fine-structured information that typically cannot be seen. Although most of the alternative SR LSMs require complicated optical geometries, SVR LSM is based on oblique scanning techniques coupled with post-processing algorithms to achieve super-resolved images of larger samples. This effective and inexpensive variant can be added to most existing LSM setups, rendering fast and super-resolved 3D structures in biological specimens. 


\section{Single-Molecule-Localization Light Sheet Microscopy}

A section has been devoted in this review for LSM modalities capable of single-molecule localization via widefield detection. LSM has emerged as a promising candidate for singlemolecule localization, owing to minimal photobleaching, the ability to tune penetration depth and the confinement of fluorescence in the imaging plane $[107,108]$. Furthermore, compatibility with high-NA detection OLs and rapid camera framerates enables excellent spatio-temporal resolution. State-of-the-art modalities such as PALM (photoactivated localization microscopy) and STORM (stochastic optical reconstruction microscopy) often suffer from photo bleaching or poor penetration depth. This is caused by their reliance on total internal reflection (TIRF) or epi-illumination excitation $[107,108]$. Single-molecule LSM modalities have been used to generate very thin light sections $(\leq 7 \mu \mathrm{m})$, to localize individual molecules of interest with high fidelity up to several nanometers (lateral localization precision $\sim 30-100 \mathrm{~nm}$, axial localization precision $\sim 135 \mathrm{~nm}$ ) [107-109]. Single-molecule-localization imaging requires a sufficient fluorophore labeling density to minimize axial overlap and high SNR (contrast) to discriminate the background from the foreground.

The first instances of the use of SPIM as a single-molecule-detection strategy was reported by Tokunaga et al. in the form of an oblique light section configuration, namely, highly inclined and laminated microscopy (HILO) [110]. As the name suggests, a light section is inclined via refraction through the coverslip in an inverted/upright fashion, at oblique angles less than the critical angle of TIRF but greater than those in epi-illumination microscopy. The diameter of the light sheet is modulated by controlling the inclination angle of the light sheet, and the authors revealed that light sectioning was achieved up to $7 \mu \mathrm{m}$ and thinner sectioning was achieved via the insertion of a field stop conjugate to the specimen plane. HILO was used to observe molecular events such as the mediation of nuclear transport after the microinjection of GFP-Importin $\beta$ into permeabilized cells. A variant of HILO, namely, variable angle epifluorescence microscopy (VAEM), was developed, corresponding to the same time scale, by Konopka et al., and this method is compatible with an inverted microscope or TIRF configuration [111]. Analogously to HILO, VAEM was tested at varying sub-critical angles less than the TIRF critical angle. The authors reported a cohort of novel imaging studies involving cortical microtubules (MT), plasma membrane dynamics in clathrin light chain-GFP (CLC-GFP) and subcellular dynamics concerning the endoplasmic reticulum and Golgi complex in root epidermal cells.

A novel LSM single-molecule strategy was reported by Gebhardt et al. in the form of reflected light sheet microscopy (RSLM), which utilized a polished AFM cantilever arm to decouple the orthogonality of a conventional LSM system [112]. The light sheet was reflected at a 90-degree angle with the help of the cantilever arm, thereby enabling compatibility with traditional coverslip/cell culture sample mounting and high-NA lenses. The authors reported an astonishing light sheet thickness of $1 \mu \mathrm{m}$, and the optical system presents exciting prospects for achieving thinner sections $(<0.5 \mu \mathrm{m})$ with the aid of higher-NA illumination and detection OLs. RSLM was evaluated with respect to HILO for visualizing single-molecule events, such as mEos2-H4 molecules in MCF-7 cell or visualizing nuclear glucocorticoid receptor binding affinity with estrogen receptors. RSLM modality was reported to achieve a $40 \%$ improvement in SNR at imaging depths up to $30 \mu \mathrm{m}$ and a twofold improvement beyond $11 \mu \mathrm{m}$, with respect to HILO.

A single-molecule-localization variant of RSLM was developed by Hu et al., substituting the AFM cantilever with a Pellin Broca prism, to decouple the conventional LSM orthogonality [113]. The light sheet was refracted through the prism from the excitation OL onto the imaging sample, at an angle of $\sim 120$ degrees with respect to the detection optical train. The authors reported a light sheet thickness of $\sim 1.8 \mu \mathrm{m}$ and were able to image heterochromatin protein HP1- $\alpha$ in the nuclei of human embryonic stem cells (HESCs).

Furthermore, the integration of varying beam intensity distributions, such as Bessel beams with selective plane illumination, can be used to perform single-molecule localization with relative ease. 
Lu et al. reported a Bessel LSM method for ultrathin light sheet confinement, resulting in a lateral full width half maximum (FWHM) of $0.54 \mu \mathrm{m}$ and an axial FWHM of $1.36 \mu \mathrm{m}$, respectively [108]. The Bessel beam intensity distribution was created via the insertion of an annular phase mask in the selective plane illumination optical train. A cylindrical lens was used to produce a one-dimensional collimated Bessel light sheet, i.e., it was used to produce optical astigmatism to prevent fluorophore interference from adjacent imaging planes. The Bessel LSM illumination was reported to resolve structures up to $100 \mathrm{~nm}$; hence, the authors were able to perform volumetric analyses of microtubules in mouse MC3T3-E1 cells and of hippocampal neurons from rat pup brains, as well as of nuclear pore complex proteins (POM121 and Nup153).

Hence, LSM is rapidly developing as a single-molecule-localization technique due to its inherently high SNR and high penetration depth. The modality is empowering biologists to understand nanoscale mechanisms with a high degree of customization, that was previously restricted in the academic environment.

\section{Conclusions}

SR LSM offers monumental advantages over aberration-prone confocal and widefield microscopy, such as rapid optical sectioning and the ability to sample volumetric biological events in vivo or ex vivo with very high spatio-temporal resolutions. Combined with tissue-clearing or expansion methods, LSM allows for the opportunity to investigate molecular structure and function across different scales that were previously unable to be reconstructed without aberrations induced by tissue. In addition, volumetric imaging over time of LSM allows for the dynamic sampling of morphogenesis in various animal models, unaffected by predicaments such as the working distance of the imaging plane or the magnification required by biological applications. Combining LSM with recently developed super-resolution imaging techniques allows the visualization of biomolecular structures in nanometer-scale resolutions, thereby surpassing the diffraction limit in fluorescence microscopy, with higher accuracy. The integration of Bessel beams and Gaussian beams has proven to successfully assist in resolving molecular elements that cannot be resolved at diffraction-limited resolutions. In summary, SR LSM overcomes several pivotal microscopy drawbacks. ASLSM allows for a longer penetration depth without an NA tradeoff; OPM provides an epi-illumination mounting strategy for LSM, enabling better access to conventional cell cultures; SR LLSM offers unparalleled spatio-temporal resolution; and SVR LSM allows for fast, high-throughput volumetric imaging of cleared whole organs at subcellular levels of resolution. Thus, there are exciting prospects for non-invasive multi-dimensional imaging, with ample research occurring in various fields.

Funding: This study was supported by grants from AHA 18CDA34110150 (J.L.) and NSF 1936519 (J.L.).

Conflicts of Interest: The authors declare no conflict of interest.

\section{References}

1. Agocs, E.; Attota, R.K. Enhancing optical microscopy illumination to enable quantitative imaging. Sci. Rep. 2018, 8, 4782. [CrossRef]

2. Reigoto, A.M.; Andrade, S.A.; Seixas, M.C.R.R.; Costa, M.L.; Mermelstein, C. A comparative study on the use of microscopy in pharmacology and cell biology research. PLOS ONE 2021, 16, e0245795. [CrossRef]

3. Karzbrun, E.; Kshirsagar, A.; Cohen, S.R.; Hanna, J.H.; Reiner, O. Human brain organoids on a chip reveal the physics of folding. Nat. Phys. 2018, 14, 515-522. [CrossRef]

4. Rios, A.C.; Clevers, H. Imaging organoids: A bright future ahead. Nat. Methods 2018, 15, 24-26. [CrossRef]

5. Figueroa, B.; Xu, F.X.; Hu, R.; Men, S.; Fu, D. Quantitative Imaging of Intracellular Density with Ratiometric Stimulated Raman Scattering Microscopy. bioRxiv 2021.

6. Yang, W.; Carrillo-Reid, L.; Bando, Y.; Peterka, D.S.; Yuste, R. Simultaneous two-photon imaging and two-photon optogenetics of cortical circuits in three dimensions. ELife 2018, 7, e32671. [CrossRef]

7. Joshi, J.; Rubart, M.; Zhu, W. Optogenetics: Background, methodological advances and potential applications for cardiovascular research and medicine. Front. Bioeng. Biotechnol. 2020, 7, 466. [CrossRef]

8. Power, R.M.; Huisken, J. A guide to light-sheet fluorescence microscopy for multiscale imaging. Nat. Methods 2017, 14, 360-373. [CrossRef]

9. Thorn, K. A quick guide to light microscopy in cell biology. Mol. Biol. Cell 2016, 27, 219-222. [CrossRef] 
10. Thorn, K. Genetically encoded fluorescent tags. Mol. Biol. Cell 2017, 28, 848-857. [CrossRef]

11. Chakraborty, T.; Driscoll, M.K.; Jeffery, E.; Murphy, M.M.; Roudot, P.; Chang, B.-J.; Vora, S.; Wong, W.M.; Nielson, C.D.; Zhang, H.; et al. Light-sheet microscopy of cleared tissues with isotropic, subcellular resolution. Nat. Methods 2019, 16, 1109-1113. [CrossRef]

12. Dean, K.M.; Roudot, P.; Reis, C.R.; Welf, E.S.; Mettlen, M.; Fiolka, R. Diagonally scanned light-sheet microscopy for fast volumetric imaging of adherent cells. Biophys. J. 2016, 110, 1456-1465. [CrossRef]

13. Kim, J.; Wojcik, M.; Wang, Y.; Moon, S.; Zin, E.A.; Marnani, N.; Newman, Z.L.; Flannery, J.G.; Xu, K.; Zhang, X. Oblique-plane single-molecule localization microscopy for tissues and small intact animals. Nat. Methods 2019, 16, 853-857. [CrossRef]

14. Sapoznik, E.; Chang, B.-J.; Huh, J.; Ju, R.J.; Azarova, E.V.; Pohlkamp, T.; Welf, E.S.; Broadbent, D.; Carisey, A.F.; Stehbens, S.J.; et al. A versatile oblique plane microscope for large-scale and high-resolution imaging of subcellular dynamics. ELife 2020, 9, e57681. [CrossRef]

15. Watkins, S.C.; St Croix, C.M. Light sheet imaging comes of age. J. Cell Biol. 2018, 217, 1567-1569. [CrossRef]

16. Zaqout, S.; Becker, L.-L.; Kaindl, A.M. Immunofluorescence staining of paraffin sections step by step. Front. Neuroanat. 2020, 14, 83. [CrossRef]

17. Li, N.; Zhao, R.; Sun, Y.; Ye, Z.; He, K.; Fang, X. Single-molecule imaging and tracking of molecular dynamics in living cells. Natl. Sci. Rev. 2017, 4, 739-760. [CrossRef]

18. Kohl, J.; Ng, J.; Cachero, S.; Ciabatti, E.; Dolan, M.-J.; Sutcliffe, B.; Tozer, A.; Ruehle, S.; Krueger, D.; Frechter, S.; et al. Ultrafast tissue staining with chemical tags. Proc. Natl. Acad. Sci. USA 2014, 111, E3805. [CrossRef]

19. Zhu, J.; Zhang, Z.-T.; Tang, S.-W.; Zhao, B.-S.; Li, H.; Song, J.-Z.; Li, D.; Xie, Z.; Glick, B.; Emr Scott, D. A validated set of fluorescent-protein-based markers for major organelles in yeast (saccharomyces cerevisiae). MBio 2019, 10, e01691-19. [CrossRef]

20. Crivat, G.; Taraska, J.W. Imaging proteins inside cells with fluorescent tags. Trends Biotechnol. 2012, 30, 8-16. [CrossRef]

21. Abramson, R.G.; Burton, K.R.; Yu, J.-P.J.; Scalzetti, E.M.; Yankeelov, T.E.; Rosenkrantz, A.B.; Mendiratta-Lala, M.; Bartholmai, B.J.; Ganeshan, D.; Lenchik, L.; et al. Methods and challenges in quantitative imaging biomarker development. Acad. Radiol. 2015, 22, 25-32. [CrossRef]

22. Meseguer, E.; Barberá-Tomás, D.; Benito-Amat, C.; Díaz-Faes, A.A.; Martí-Bonmatí, L. What do biomarkers add: Mapping quantitative imaging biomarkers research. Eur. J. Radiol. 2022, 146, 110052. [CrossRef]

23. Waterhouse, D.J.; Fitzpatrick, C.R.M.; Pogue, B.W.; O'Connor, J.P.B.; Bohndiek, S.E. A roadmap for the clinical implementation of optical-imaging biomarkers. Nat. Biomed. Eng. 2019, 3, 339-353. [CrossRef]

24. Selleck, M.J.; Senthil, M.; Wall, N.R. Making meaningful clinical use of biomarkers. Biomark. Insights 2017, 12, 1177271917715236. [CrossRef]

25. Carvajal-Hausdorf, D.E.; Schalper, K.A.; Neumeister, V.M.; Rimm, D.L. Quantitative measurement of cancer tissue biomarkers in the lab and in the clinic. Lab. Investig. 2015, 95, 385-396. [CrossRef]

26. Tandon, I.; Johns, S.; Woessner, A.; Perez, J.; Cross, D.; Ozkizilcik, A.; Muldoon, T.J.; Vallurupalli, S.; Padala, M.; Quinn, K.P.; et al Label-free optical biomarkers detect early calcific aortic valve disease in a wild-type mouse model. BMC Cardiovasc. Disord. 2020, 20, 521. [CrossRef]

27. Zhou, H.; Nguyen, L.; Arnesano, C.; Ando, Y.; Raval, M.; Rodgers, J.T.; Fraser, S.; Lu, R.; Shen, K. Non-invasive optical biomarkers distinguish and track the metabolic status of single hematopoietic stem cells. iScience 2020, 23, 100831. [CrossRef]

28. Jun, Y.W.; Cho, S.W.; Jung, J.; Huh, Y.; Kim, Y.; Kim, D.; Ahn, K.H. Frontiers in probing alzheimer's disease biomarkers with fluorescent small molecules. ACS Cent. Sci. 2019, 5, 209-217. [CrossRef]

29. Reshma, V.; Varsha, B.K.; Rakesh, P.; Radhika, M.B.; Soumya, M.; D’Mello, S. Aggrandizing oral submucous fibrosis grading using an adjunct special stain: A pilot study. J. Oral Maxillofac. Pathol. 2016, 20, 36-46. [CrossRef]

30. Lahiani, A.; Klaiman, E.; Grimm, O. Enabling histopathological annotations on immunofluorescent images through virtualization of hematoxylin and eosin. J. Pathol. Inform. 2018, 9, 1. [CrossRef]

31. Azevedo Tosta, T.A.; Neves, L.A.; do Nascimento, M.Z. Segmentation methods of H\&E-stained histological images of lymphoma: A review. Inform. Med. Unlocked 2017, 9, 35-43. [CrossRef]

32. Chlipala, E.; Bendzinski, C.M.; Chu, K.; Johnson, J.I.; Brous, M.; Copeland, K.; Bolon, B. Optical density-based image analysis method for the evaluation of hematoxylin and eosin staining precision. J. Histotechnol. 2020, 43, 29-37. [CrossRef]

33. Kleczek, P.; Jaworek-Korjakowska, J.; Gorgon, M. A novel method for tissue segmentation in high-resolution h\&e-stained histopathological whole-slide images. Comput. Med. Imaging Graph. 2020, 79, 101686. [CrossRef] [PubMed]

34. Hinton, J.P.; Dvorak, K.; Roberts, E.; French, W.J.; Grubbs, J.C.; Cress, A.E.; Tiwari, H.A.; Nagle, R.B. A method to reuse archived H\&E stained histology slides for a multiplex protein biomarker analysis. Methods Protoc. 2019, 2, 86. [CrossRef]

35. Boyd, A.; Cain, O.; Chauhan, A.; Webb, G.J. Medical liver biopsy: Background, indications, procedure and histopathology. Frontline Gastroenterol. 2020, 11, 40. [CrossRef]

36. Choi, M.; Kwok, S.J.J.; Yun, S.H. In vivo fluorescence microscopy: Lessons from observing cell behavior in their native environment. Physiology 2015, 30, 40-49. [CrossRef]

37. Dean, K.M.; Palmer, A.E. Advances in fluorescence labeling strategies for dynamic cellular imaging. Nat. Chem. Biol. 2014, 10, 512-523. [CrossRef]

38. Djuric, U.; Zadeh, G.; Aldape, K.; Diamandis, P. Precision histology: How deep learning is poised to revitalize histomorphology for personalized cancer care. NPJ Precis. Oncol. 2017, 1, 22. [CrossRef]

39. Cui, M.; Zhang, D.Y. Artificial intelligence and computational pathology. Lab. Investig. 2021, 101, 412-422. [CrossRef] 
40. Azam, A.S.; Miligy, I.M.; Kimani, P.K.-U.; Maqbool, H.; Hewitt, K.; Rajpoot, N.M.; Snead, D.R.J. Diagnostic concordance and discordance in digital pathology: A systematic review and meta-analysis. J. Clin. Pathol. 2021, 74, 448. [CrossRef]

41. Taqi, S.A.; Sami, S.A.; Sami, L.B.; Zaki, S.A. A review of artifacts in histopathology. J. Oral Maxillofac. Pathol. 2018, 22, 279. [CrossRef]

42. Bindhu, P.; Krishnapillai, R.; Thomas, P.; Jayanthi, P. Facts in artifacts. J. Oral Maxillofac. Pathol. 2013, 17, 397-401. [CrossRef] [PubMed]

43. Li, D.; Hui, H.; Zhang, Y.; Tong, W.; Tian, F.; Yang, X.; Liu, J.; Chen, Y.; Tian, J. Deep learning for virtual histological staining of bright-field microscopic images of unlabeled carotid artery tissue. Mol. Imaging Biol. 2020, 22, 1301-1309. [CrossRef]

44. Kuru, K. Optimization and enhancement of H\&E stained microscopical images by applying bilinear interpolation method on lab color mode. Theor. Biol. Med. Model. 2014, 11, 9. [CrossRef]

45. Rivenson, Y.; de Haan, K.; Wallace, W.D.; Ozcan, A. Emerging advances to transform histopathology using virtual staining. BME Front. 2020, 2020, 9647163. [CrossRef]

46. Treuting, P.M.; Snyder, J.M.; Ikeno, Y.; Schofield, P.N.; Ward, J.M.; Sundberg, J.P. The vital role of pathology in improving reproducibility and translational relevance of aging studies in rodents. Vet. Pathol. 2016, 53, 244-249. [CrossRef] [PubMed]

47. Husain, S.A.; King, K.L.; Batal, I.; Dube, G.K.; Hall, I.E.; Brennan, C.; Stokes, M.B.; Crew, R.J.; Carpenter, D.; Alvarado Verduzco, H.; et al. Reproducibility of deceased donor kidney procurement biopsies. Clin. J. Am. Soc. Nephrol. 2020, 15, 257. [CrossRef] [PubMed]

48. Ward, J.M.; Schofield, P.N.; Sundberg, J.P. Reproducibility of histopathological findings in experimental pathology of the mouse: A sorry tail. Lab. Anim. 2017, 46, 146-151. [CrossRef]

49. Lauber, D.T.; Fülöp, A.; Kovács, T.; Szigeti, K.; Máthé, D.; Szijártó, A. State of the art in vivo imaging techniques for laboratory animals. Lab. Anim. 2017, 51, 465-478. [CrossRef]

50. Dunst, S.; Tomancak, P. Imaging flies by fluorescence microscopy: Principles, technologies, and applications. Genetics 2019, 211, 15-34. [CrossRef]

51. Vedula, V.; Lee, J.; Xu, H.; Kuo, C.-C.J.; Hsiai, T.K.; Marsden, A.L. A method to quantify mechanobiologic forces during zebrafish cardiac development using 4-d light sheet imaging and computational modeling. PLoS Comput. Biol. 2017, 13, e1005828. [CrossRef] [PubMed]

52. Mertz, J. Optical sectioning microscopy with planar or structured illumination. Nat. Methods 2011, 8, 811-819. [CrossRef] [PubMed]

53. Shaw, P.J. Comparison of widefield/deconvolution and confocal microscopy for three-dimensional imaging. In Handbook of Biological Confocal Microscopy; Pawley, J.B., Ed.; Springer: Boston, MA, USA, 2006; pp. 453-467. ISBN 978-0-387-45524-2.

54. Myers, K.A.; Janetopoulos, C. Recent advances in imaging subcellular processes. F1000Research 2016, 5. [CrossRef]

55. Schermelleh, L.; Heintzmann, R.; Leonhardt, H. A guide to super-resolution fluorescence microscopy. J. Cell Biol. 2010, 190, 165-175. [CrossRef] [PubMed]

56. Fischer, R.S.; Wu, Y.; Kanchanawong, P.; Shroff, H.; Waterman, C.M. Microscopy in 3D: A biologist's toolbox. Trends Cell Biol. 2011, 21, 682-691. [CrossRef] [PubMed]

57. Huszka, G.; Gijs, M.A.M. Super-resolution optical imaging: A comparison. Micro Nano Eng. 2019, 2, 7-28. [CrossRef]

58. Vangindertael, J.; Camacho, R.; Sempels, W.; Mizuno, H.; Dedecker, P.; Janssen, K.P.F. An introduction to optical super-resolution microscopy for the adventurous biologist. Methods Appl. Fluoresc. 2018, 6, 022003. [CrossRef]

59. Wolenski, J.S.; Julich, D. Fluorescence microscopy gets faster and clearer: Roles of photochemistry and selective illumination. Yale J. Biol. Med. 2014, 87, 21-32.

60. Teranikar, T.; Messerschmidt, V.; Lim, J.; Bailey, Z.; Chiao, J.-C.; Cao, H.; Liu, J.; Lee, J. Correcting anisotropic intensity in light sheet images using dehazing and image morphology. APL Bioeng. 2020, 4, 036103. [CrossRef]

61. Teranikar, T.; Villarreal, C.; Salehin, N.; Lim, J.; Ijaseun, T.; Cao, H.; Chuong, C.; Lee, J. Feature detection to segment cardiomyocyte nuclei for investigating cardiac contractility. bioRxiv 2021. [CrossRef]

62. Ding, Y.; Lee, J.; Ma, J.; Sung, K.; Yokota, T.; Singh, N.; Dooraghi, M.; Abiri, P.; Wang, Y.; Kulkarni, R.P.; et al. Light-sheet fluorescence imaging to localize cardiac lineage and protein distribution. Sci. Rep. 2017, 7, 42209. [CrossRef] [PubMed]

63. Ponsetto, J.L.; Bezryadina, A.; Wei, F.; Onishi, K.; Shen, H.; Huang, E.; Ferrari, L.; Ma, Q.; Zou, Y.; Liu, Z. Experimental demonstration of localized plasmonic structured illumination microscopy. ACS Nano 2017, 11, 5344-5350. [CrossRef] [PubMed]

64. Richter, V.; Piper, M.; Wagner, M.; Schneckenburger, H. Increasing resolution in live cell microscopy by structured illumination (SIM). Appl. Sci. 2019, 9, 1188. [CrossRef]

65. Wu, Y.; Shroff, H. Faster, sharper, and deeper: Structured illumination microscopy for biological imaging. Nat. Methods 2018, 15, 1011-1019. [CrossRef]

66. Gohn-Kreuz, C.; Rohrbach, A. Light needles in scattering media using self-reconstructing beams and the STED principle. Optica 2017, 4, 1134-1142. [CrossRef]

67. Spahn, C.; Grimm, J.B.; Lavis, L.D.; Lampe, M.; Heilemann, M. Whole-cell, 3D, and multicolor STED imaging with exchangeable fluorophores. Nano Lett. 2019, 19, 500-505. [CrossRef]

68. Xie, L.; Dong, P.; Chen, X.; Hsieh, T.-H.S.; Banala, S.; De Marzio, M.; English, B.P.; Qi, Y.; Jung, S.K.; Kieffer-Kwon, K.-R.; et al. 3D ATAC-PALM: Super-resolution imaging of the accessible genome. Nat. Methods 2020, 17, 430-436. [CrossRef]

69. Wäldchen, F.; Schlegel, J.; Götz, R.; Luciano, M.; Schnermann, M.; Doose, S.; Sauer, M. Whole-cell imaging of plasma membrane receptors by 3D lattice light-sheet DSTORM. Nat. Commun. 2020, 11, 887. [CrossRef]

70. Xu, H.; Tong, Z.; Ye, Q.; Sun, T.; Hong, Z.; Zhang, L.; Bortnick, A.; Cho, S.; Beuzer, P.; Axelrod, J.; et al. Molecular organization of mammalian meiotic chromosome axis revealed by expansion STORM microscopy. Proc. Natl. Acad. Sci. USA 2019, 116, 18423-18428. [CrossRef] 
71. Xu, J.; Ma, H.; Liu, Y. Stochastic optical reconstruction microscopy (STORM). Curr. Protoc. Cytom. 2017, 81, 12-46. [CrossRef]

72. Lambert, T.J.; Waters, J.C. Navigating challenges in the application of superresolution microscopy. J. Cell Biol. 2016, $216,53-63$. [CrossRef] [PubMed]

73. Zheng, X.; Zhou, J.; Wang, L.; Wang, M.; Wu, W.; Chen, J.; Qu, J.; Gao, B.Z.; Shao, Y. Current challenges and solutions of super-resolution structured illumination microscopy. APL Photonics 2021, 6, 020901. [CrossRef]

74. Möckl, L.; Moerner, W.E. Super-resolution microscopy with single molecules in biology and beyond-essentials, current trends, and future challenges. J. Am. Chem. Soc. 2020, 142, 17828-17844. [CrossRef]

75. Bishop, K.W.; Glaser, A.K.; Liu, J.T.C. Performance tradeoffs for single- and dual-objective open-top light-sheet microscope designs: A simulation-based analysis. Biomed. Opt. Express 2020, 11, 4627-4650. [CrossRef] [PubMed]

76. Tosheva, K.L.; Yuan, Y.; Matos Pereira, P.; Culley, S.; Henriques, R. Between life and death: Strategies to reduce phototoxicity in super-resolution microscopy. J. Phys. D Appl. Phys. 2020, 53, 163001. [CrossRef] [PubMed]

77. Chen, B.-C.; Legant, W.R.; Wang, K.; Shao, L.; Milkie, D.E.; Davidson, M.W.; Janetopoulos, C.; Wu, X.S.; Hammer, J.A., 3rd; Liu, Z.; et al. Lattice light-sheet microscopy: Imaging molecules to embryos at high spatiotemporal resolution. Science 2014, 346, 1257998. [CrossRef] [PubMed]

78. Chang, B.-J.; Dean, K.M.; Fiolka, R. Systematic and quantitative comparison of lattice and gaussian light-sheets. Opt. Express 2020, 28, 27052-27077. [CrossRef]

79. Santi, P.A. Light sheet fluorescence microscopy: A review. J. Histochem. Cytochem. 2011, 59, 129-138. [CrossRef]

80. Gustavsson, A.-K.; Petrov, P.N.; Lee, M.Y.; Shechtman, Y.; Moerner, W.E. Tilted light sheet microscopy with 3D point spread functions for single-molecule super-resolution imaging in mammalian cells. Int. Soc. Opt. Photonics 2018, 10500, 105000M. [CrossRef]

81. Fei, P.; Nie, J.; Lee, J.; Ding, Y.; Li, S.; Yu, Z.; Zhang, H.; Hagiwara, M.; Yu, T.; Segura, T.; et al. Sub-voxel light-sheet microscopy for high-resolution, high-throughput volumetric imaging of large biomedical specimens. bioRxiv 2018. [CrossRef]

82. Olarte, O.E.; Andilla, J.; Gualda, E.J.; Loza-Alvarez, P. Light-sheet microscopy: A tutorial. Adv. Opt. Photon. 2018, 10, 111-179. [CrossRef]

83. Remacha, E.; Friedrich, L.; Vermot, J.; Fahrbach, F.O. How to define and optimize axial resolution in light-sheet microscopy: A simulation-based approach. Biomed. Opt. Express 2019, 11, 8-26. [CrossRef] [PubMed]

84. Becker, K.; Saghafi, S.; Pende, M.; Sabdyusheva-Litschauer, I.; Hahn, C.M.; Foroughipour, M.; Jährling, N.; Dodt, H.-U. Deconvolution of light sheet microscopy recordings. Sci. Rep. 2019, 9, 17625. [CrossRef] [PubMed]

85. Huisken, J.; Swoger, J.; Del Bene, F.; Wittbrodt, J.; Stelzer, E.H. Optical sectioning deep inside live embryos by selective plane illumination microscopy. Science 2004, 305, 1007-1009. [CrossRef]

86. Dean, K.M.; Roudot, P.; Welf, E.S.; Danuser, G.; Fiolka, R. Deconvolution-free subcellular imaging with axially swept light sheet microscopy. Biophys. J. 2015, 108, 2807-2815. [CrossRef]

87. Wu, Y.; Chandris, P.; Winter, P.W.; Kim, E.Y.; Jaumouillé, V.; Kumar, A.; Guo, M.; Leung, J.M.; Smith, C.; Rey-Suarez, I.; et al Simultaneous multiview capture and fusion improves spatial resolution in wide-field and light-sheet microscopy. Optica 2016, 3, 897-910. [CrossRef]

88. Yu, T.; Zhu, J.; Li, D.; Zhu, D. Physical and chemical mechanisms of tissue optical clearing. iScience 2021, 24, 102178. [CrossRef]

89. Jing, D.; Zhang, S.; Luo, W.; Gao, X.; Men, Y.; Ma, C.; Liu, X.; Yi, Y.; Bugde, A.; Zhou, B.O.; et al. Tissue Clearing of both hard and soft tissue organs with the PEGASOS method. Cell Res. 2018, 28, 803-818. [CrossRef]

90. Chen, Y.; Chen, M.; Zhu, L.; Wu, J.Y.; Du, S.; Li, Y. Measure and model a 3-D space-variant psf for fluorescence microscopy image deblurring. Opt. Express 2018, 26, 14375-14391. [CrossRef]

91. Chakraborty, T.; Driscoll, M.; Murphy, M.; Roudot, P.; Chang, B.-J.; Vora, S.; Wong, W.M.; Nielson, C.; Zhang, H.; Zhemkov, V.; et al Light-sheet microscopy with isotropic, sub-micron resolution and solvent-independent large-scale imaging. bioRxiv 2019. [CrossRef]

92. Landry, J.; Hamann, S.; Solgaard, O. High-speed axially swept light sheet microscopy using a linear MEMS phased array for isotropic resolution. J. Biomed. Opt. 2020, 25, 106504. [CrossRef] [PubMed]

93. Gustavsson, A.-K.; Petrov, P.N.; Lee, M.Y.; Shechtman, Y.; Moerner, W.E. 3D single-molecule super-resolution microscopy with a tilted light sheet. Nat. Commun. 2018, 9, 123. [CrossRef] [PubMed]

94. Yang, B.; Lange, M.; Millett-Sikking, A.; Solak, A.C.; Kumar, S.V.; Wang, W.; Kobayashi, H.; McCarroll, M.N.; Whitehead, L.W.; Fiolka R.P.; et al. High-resolution, large imaging volume, and multi-view single objective light-sheet microscopy. bioRxiv 2021. [CrossRef]

95. Kumar, M.; Kozorovitskiy, Y. Tilt (in)variant lateral scan in oblique plane microscopy: A geometrical optics approach. Biomed. Opt. Express 2020, 11, 3346-3359. [CrossRef] [PubMed]

96. Dev, V.; Reddy, A.N.K.; Ustinov, A.V.; Khonina, S.N.; Pal, V. Autofocusing and self-healing properties of aberration laser beams in a turbulent media. Phys. Rev. Appl. 2021, 16, 014061. [CrossRef]

97. Mimori-Kiyosue, Y. Imaging mitotic processes in three dimensions with lattice light-sheet microscopy. Chromosome Res. 2021, 29, 37-50. [CrossRef]

98. Liu, T.-L.; Upadhyayula, S.; Milkie, D.E.; Singh, V.; Wang, K.; Swinburne, I.A.; Mosaliganti, K.R.; Collins, Z.M.; Hiscock, T.W.; Shea, J.; et al. Observing the cell in its native state: Imaging subcellular dynamics in multicellular organisms. Science 2018, 360, eaaq1392. [CrossRef]

99. Planchon, T.A.; Gao, L.; Milkie, D.E.; Davidson, M.W.; Galbraith, J.A.; Galbraith, C.G.; Betzig, E. Rapid three-dimensional isotropic imaging of living cells using bessel beam plane illumination. Nat. Methods 2011, 8, 417-423. [CrossRef]

100. Gao, R.; Asano, S.M.; Upadhyayula, S.; Pisarev, I.; Milkie, D.E.; Liu, T.-L.; Singh, V.; Graves, A.; Huynh, G.H.; Zhao, Y.; et al. Cortical column and whole-brain imaging with molecular contrast and nanoscale resolution. Science 2019, 363, eaau8302. [CrossRef] 
101. Chen, F.; Tillberg, P.W.; Boyden, E.S. Optical imaging. expansion microscopy. Science 2015, 347, 543-548. [CrossRef]

102. Kunz, T.C.; Götz, R.; Gao, S.; Sauer, M.; Kozjak-Pavlovic, V. Using expansion microscopy to visualize and characterize the morphology of mitochondrial cristae. Front. Cell Dev. Biol. 2020, 8, 617. [CrossRef] [PubMed]

103. Parra-Damas, A.; Saura, C.A. Tissue clearing and expansion methods for imaging brain pathology in neurodegeneration: From circuits to synapses and beyond. Front. Neurosci. 2020, 14, 914. [CrossRef] [PubMed]

104. Nie, J.; Liu, S.; Yu, T.; Li, Y.; Ping, J.; Peng, W.; Zhao, F.; Huang, Y.; Mei, W.; Zeng, S.; et al. Fast, 3D Isotropic imaging of whole mouse brain using multiangle-resolved subvoxel SPIM. Adv. Sci. 2020, 7, 1901891. [CrossRef] [PubMed]

105. Zhao, F.; Yang, Y.; Li, Y.; Jiang, H.; Xie, X.; Yu, T.; Liu, Q.; Zhang, H.; Jia, H.; Liu, S.; et al. Efficient and cost-effective 3D cellular imaging by sub-voxel-resolving light-sheet add-on microscopy. J. Biophotonics 2020, 13, e201960243. [CrossRef] [PubMed]

106. Guan, Z.; Lee, J.; Jiang, H.; Dong, S.; Jen, N.; Hsiai, T.; Ho, C.-M.; Fei, P. Compact plane illumination plugin device to enable light sheet fluorescence imaging of multi-cellular organisms on an inverted wide-field microscope. Biomed. Opt. Express 2016, 7, 194-208. [CrossRef] [PubMed]

107. Hu, Y.S.; Zimmerley, M.; Li, Y.; Watters, R.; Cang, H. Single-molecule Super-resolution Light-sheet Microscopy. Chem. Phys. Chem. 2014, 15, 577-586. [CrossRef] [PubMed]

108. Lu, C.-H.; Tang, W.-C.; Liu, Y.-T.; Chang, S.-W.; Wu, F.C.M.; Chen, C.-Y.; Tsai, Y.-C.; Yang, S.-M.; Kuo, C.-W.; Okada, Y.; et al. Lightsheet localization microscopy enables fast, large-scale, and Three-Dimensional super-resolution imaging. Commun. Biol. 2019, 2, 177. [CrossRef]

109. Cella Zanacchi, F.; Lavagnino, Z.; Perrone Donnorso, M.; Del Bue, A.; Furia, L.; Faretta, M.; Diaspro, A. Live-cell 3D superresolution imaging in thick biological samples. Nat. Methods 2011, 8, 1047-1049. [CrossRef]

110. Tokunaga, M.; Imamoto, N.; Sakata-Sogawa, K. Highly inclined thin illumination enables clear single-molecule imaging in cells. Nat. Methods 2008, 5, 159-161. [CrossRef]

111. Konopka, C.; Bednarek, S. Variable-angle epifluorescence microscopy: A new way to look at protein dynamics in the plant cell cortex. Plant J. Cell Mol. Biol. 2008, 53, 186-196. [CrossRef]

112. Gebhardt, J.C.M.; Suter, D.M.; Roy, R.; Zhao, Z.W.; Chapman, A.R.; Basu, S.; Maniatis, T.; Xie, X.S. Single-molecule imaging of transcription factor binding to DNA in live mammalian cells. Nat. Methods 2013, 10, 421-426. [CrossRef] [PubMed]

113. Hu, Y.S.; Zhu, Q.; Elkins, K.; Tse, K.; Li, Y.; Fitzpatrick, J.A.J.; Verma, I.M.; Cang, H. Light-sheet bayesian microscopy enables deep-cell super-resolution imaging of heterochromatin in live human embryonic stem cells. Opt. Nanoscopy $2013,2,7$. [CrossRef] [PubMed] 